\title{
Structural Characterization of Cyclic Isoprene Trimer
}

\author{
Yasuyuki TANAKA, Hisaya SATO, Yasunobu NAKAFUTAMI, \\ Hitoshi IWASAKI, and Takanao TAKETOMI* \\ Department of Textiles and Polymer Science, \\ Faculty of Technology, Koganei, Tokyo 184, Japan \\ *Takasago Perfumery Co. Ltd., Kamata, Ohta, Tokyo 144, Japan
}

(Received March 9, 1982)

\begin{abstract}
A study was made on the isomeric structure of trimethyl-cyclododecatriene (TMCDT) prepared by oligomerization of isoprene with $\left(\mathrm{C}_{5} \mathrm{H}_{8}\right)_{2} \mathrm{Mg}-\mathrm{AlCl}_{3}-\mathrm{TiCl}_{4}-\mathrm{CH}_{3} \mathrm{SCH}_{3}$ as a catalyst. The ${ }^{1} \mathrm{H}$ and ${ }^{13} \mathrm{C}$ NMR spectra of this compound showed the presence of one cis and two trans double bonds. The partial ozonolysis of TMCDT followed by the reductive degradation to alcohols gave three products corresponding to a linear trimer and two dimers of isoprene. These products were fractionated by liquid chromatography. ${ }^{13} \mathrm{C}$ NMR measurements showed these partial ozonolysis products to be 5-methyl-cis-5-decene-2,9-diol, 5-methyl-trans-4-nonene-1,8-diol, and 5,8-dimethyl-trans,cis-4,8-tridecadiene-1,12-diol, indicating that one of the trans isoprene units was linked to the other isoprene units in a head-to-head and tail-to-tail fashion. This was also confirmed by an infrared measurement of hydrogenated TMCDT. The TMCDT was concluded to be 1,5,9-trimethyl-cis,trans,trans-1,5,10-cyclododecatriene.

KEY WORDS Cyclic Trimer $/{ }^{13} \mathrm{C}$ NMR / Partial Ozonolysis / Geometric Isomerism / Head-Tail Alignment / Fractionation /
\end{abstract}

Trimethylcyclododecatriene (TMCDT) was prepared by oligomerization of isoprene with Ziegler catalysts. $^{1-4}$ Twelve isomers can be expected for TMCDT in consideration of the geometric isomerism and the head-to-tail, tail-to-tail, and headto-head arrangement of the isoprene units. The TMCDT so far obtained is considered to be one of these isomers or a mixture of these. The isolation and structural characterization of the TMCDT isomers have not yet been reported.

The geometric isomerism in TMCDT can be determined by ${ }^{1} \mathrm{H}$ NMR and infrared spectroscopies. The arrangement of the isoprene units may be determined by ozonolysis-gas chromatography. ${ }^{4}$ However, it is very difficult to characterize the isomers by these methods, since they contain different linkages such as cis-1,4-trans-1,4, cis-4,1trans-1,4, cis-4,1-trans-4,1, and cis-1,4-trans-4,1.

We investigated ${ }^{13} \mathrm{C}$ NMR spectra of cis-trans isomerized polyisoprene, ${ }^{5,6}$ hydrogenated polyisoprene, ${ }^{7}$ polyprenol, ${ }^{8}$ and low molecular weight homologues of polyprenol ${ }^{9}$ and successfully deter- mined the arrangement of cis-1,4 and trans-1,4 units. In this work, structural characterization of TMCDT was carried out by ${ }^{13} \mathrm{C}$ NMR analysis of the partial ozonolysis products of TMCDT.

\section{EXPERIMENTAL}

\section{Materials}

Oligomerization of isoprene was conducted at $45^{\circ} \mathrm{C}$ in a glass ampoule under nitrogen atmosphere using $\left(\mathrm{C}_{5} \mathrm{H}_{8}\right)_{2} \mathrm{Mg}-\mathrm{AlCl}_{3}-\mathrm{TiCl}_{4}-\mathrm{CH}_{3} \mathrm{SCH}_{3}$ in toluene as a catalyst. ${ }^{10}$ The resulting TMCDT was purified by distillation under reduced pressure; $138^{\circ} \mathrm{C} / 13$ Torr, $n_{d}=1.5120$. The TMCDT was found to be $92.3 \%$ pure by gas chromatographic measurement. Hydrogenation of TMCDT was carried out for $5 \mathrm{~h}$ under hydrogen atmosphere $20 \mathrm{~kg} / \mathrm{cm}^{2}$ ) using Raney nickel.

\section{Ozonolysis and Fractionation}

Partial ozonolysis of TMCDT was carried out by bubbling $1 / 3$ equivalent of ozone $(1.5 \%$ in oxygen) 
into a methylene chloride solution of TMCDT $(500 \mathrm{mg} / 100 \mathrm{ml})$ at $-20^{\circ} \mathrm{C}$. The resulting ozonide was reduced to alcohols by adding it dropwise into $\mathrm{LiAlH}_{4}$ in ethyl ether. The ozonolysis product was fractionated into linear alcohols corresponding to the trimer and dimer of isoprene by gel permeation chromatography using chloroform as an eluent. The fractions were further separated into isomers by liquid chromatography using methanol as an eluent. These fractionations were carried out in a preparative column $(600 \times 21.2$ i.d. $\mathrm{mm})$ packed with a styrene-divinylbenzene gel having an exclusion limit of 3000 for polystyrene. ${ }^{11}$

\section{Measurements}

${ }^{13} \mathrm{C}$ NMR spectra were obtained at room temperature in deuterochloroform or methanol $(5-10$ w/v \%) using a JEOL-JNM FX-200 at $50.1 \mathrm{MHz}$. Chemical shifts were referred to tetramethylsilane added as an internal standard. All spectra were proton noise decoupled and obtained with multiple scans at a pulse repetition time of $5 \mathrm{~s} .{ }^{1} \mathrm{H}$ NMR spectra at $200 \mathrm{MHz}$ were obtained in deuterobenzene at room temperature.

\section{RESULTS AND DISCUSSION}

\section{Geometric Isomerism}

In the ${ }^{1} \mathrm{H}$ NMR spectrum of TMCDT shown in Figure 1 , the signals at 1.68 and $1.55-1.58 \mathrm{ppm}$ were assigned to the methyl protons in the cis and trans isoprene units, respectively. The latter peaks appeared as two doublets. This splitting is attributed to the spin-spin coupling of the methyl pro- tons with the olefinic proton $(J=1.5 \mathrm{~Hz})$. The two signals associated with the trans methyl proton indicate that TMCDT contains two types of methyl groups located in chemically and/or sterically different environments. The intensity ratio of the $c i s$ to trans methyl signals was 1 to 2 . A small signal at $1.49 \mathrm{ppm}$ was considered due to the methyl protons in a contaminated trans, trans, trans-TMCDT. Its relative intensity was consistent with the relative amount of this isomer determined by gas chromatography.

On the basis of these findings, the four types of isomers (A) to (D), which are shown below and differ with respect to the arrangement of the $c i s$ and trans isoprene units, were chosen as relevant models for TMCDT.

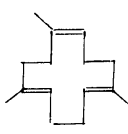

(A)

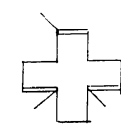

(B)

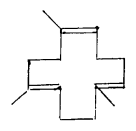

(C)

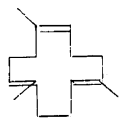

(D)

\section{Arrangement of Isoprene Units}

Hydrogenation of the double bonds in TMCDT should lead the isomers (A), (B), and (C) to 1,4,8trimethylcyclododecane and (D) to 1,5,9-trimethylcyclododecane. The infrared spectrum of the hydrogenated TMCDT exhibited absorption bands at 752 and $732 \mathrm{~cm}^{-1}$, which are characteristic of the rocking bands of $-\left(\mathrm{CH}_{2}\right)_{2}-$ and $-\left(\mathrm{CH}_{2}\right)_{3}-$ $+-\left(\mathrm{CH}_{2}\right)_{4}-$ sequences, respectively. ${ }^{12,13}$ The gas chromatogram of the hydrogenated TMCDT measured with a $30 \mathrm{~m}$ glass capillary column coated with a fatty acid polyester (FFAP) showed four

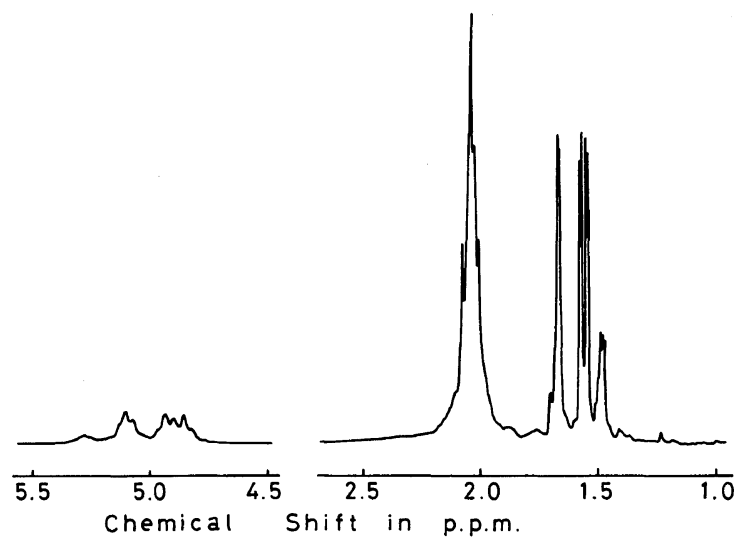

Figure 1. ${ }^{1} \mathrm{H}$ NMR spectrum of TMCDT in $\mathrm{C}_{6} \mathrm{D}_{6}$ solution. 
main peaks of similar intensity. This indicates the presence of four diastereomers in the hydrogenated TMCDT; the 1,4,8-isomer should give four diastereomers, whereas the 1,5,9-isomer should give only two.

These findings indicate that the isomers (A), (B), and $(C)$ are the correct choices for the structure of TMCDT. In these isomers, one isoprene unit is linked to the other isoprene units in a head-to-head and tail-to-tail fashion. The presence of the head-tohead and tail-to-tail linkages in TMCDT has also been reported by Morikawa and $\mathrm{Kitazumi}^{4}$ who used ozonolysis and gas chromatography. However, the authors made no determination of the arrangement of the cis and trans isoprene units.

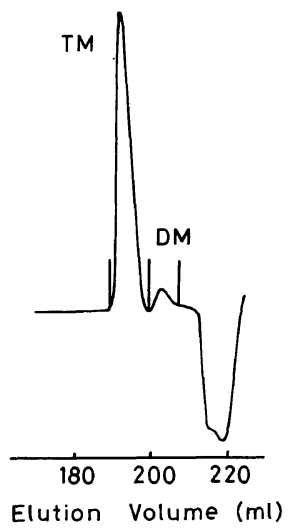

Figure 2. Fractionation of partial ozonolysis products by gel permeation chromatography, using chloroform as eluent.

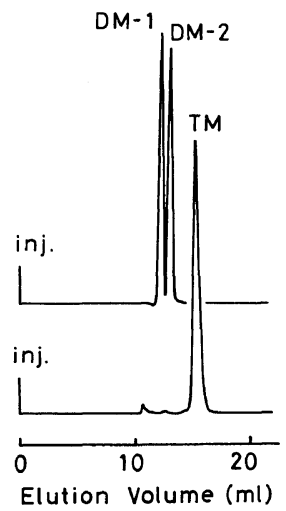

Figure 3. Separation of partial ozonolysis products by liquid chromatography, using methanol as eluent.

\section{Arrangement of Cis and Trans Units}

The partial ozonolysis products from TMCDT were separated into two fractions corresponding to the linear isoprene trimer (TM) and dimer (DM) by gel permeation chromatography (Figure 2). The molecular volumes of these compounds were agreed with those of the model compounds prepared by partial ozonolysis of cis-1,4 and trans-1,4 polyisoprenes. ${ }^{14}$ The trimer and dimer were further fractionated by liquid chromatography using methanol as an eluent (Figure 3). It was reported that a mixture of farnesol isomers was separated into ciscis-, cis-trans-+trans-cis-, and trans-trans-isomers by liquid chromatography using methanol as an eluent. ${ }^{15}$ The dimer was separated into two components of the equivalent amount, DM-1 and DM-2, while the trimer showed only one peak.

The ${ }^{13} \mathrm{C}$ NMR spectrum of DM-2 exhibited 18 major peaks as shown in Figure 4-A. On the other hand, the dimers prepared by partial ozonolysis of

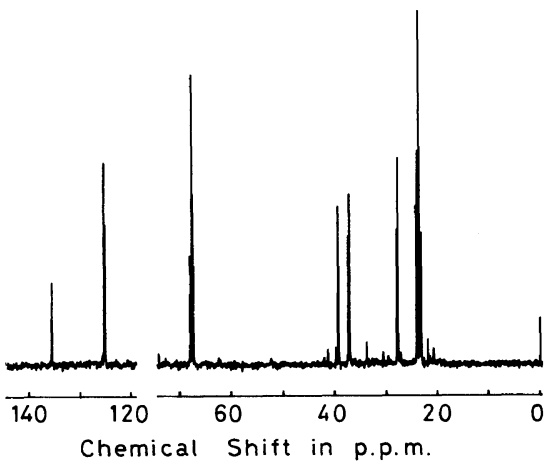

(A)

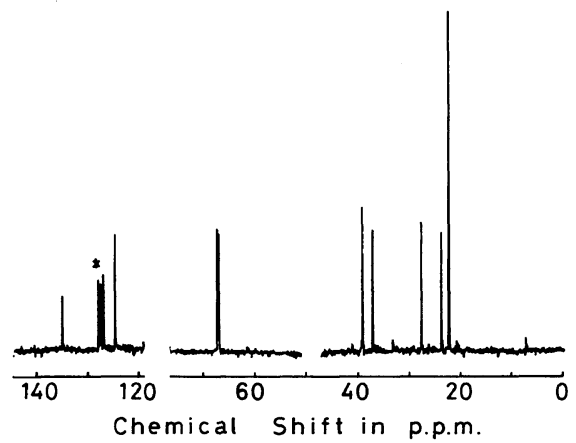

(B)

Figure 4. ${ }^{13} \mathrm{C}$ NMR spectra of the partial ozonolysis product (DM-2) in chloroform solution (A) and in methanol solution (B). (* Signals associated with $\mathrm{C}_{6} \mathrm{D}_{6}$.) 
Y. TANAKA et al.

Table I. Assignment of the carbon atoms in partial ozonolysis products

\begin{tabular}{|c|c|c|c|c|c|}
\hline \multicolumn{2}{|c|}{ DM-1 } & \multicolumn{2}{|c|}{ DM-2 } & \multicolumn{2}{|c|}{$\mathrm{TM}$} \\
\hline Chemical shift* & Assign. & Chemical shift* & Assign. & Chemical shift* & Assign. \\
\hline \multirow[t]{2}{*}{135.69} & 0 & $135.60\}$ & \multirow{2}{*}{2} & 135.10 & $\{2 \mathrm{~T}$ \\
\hline & 2 & $135.48\}$ & & $135.07\}$ & $2 \mathrm{C}$ \\
\hline \multirow[t]{2}{*}{124.18} & 3 & $125.26\}$ & \multirow[b]{2}{*}{3} & 124.46 & $3 \mathrm{~T}$ \\
\hline & & $125.09\}$ & & 123.61 & $3 \mathrm{C}$ \\
\hline \multirow[t]{3}{*}{68.00} & $2 \mathrm{~L}$ & 67.83 & \multirow{3}{*}{$\begin{array}{l}2 \mathrm{~L} \\
2 \mathrm{R}\end{array}$} & 67.37 & $2 \mathrm{R}$ \\
\hline & & $67.57\}$ & & & \\
\hline & & 67.36 & & & \\
\hline \multirow[t]{3}{*}{62.57} & $3 R$ & & \multirow{3}{*}{$1 \mathrm{R}$} & 61.92 & $3 \mathrm{~L}$ \\
\hline & & $39.42\}$ & & 39.37 & $1 R$ \\
\hline & & $39.36\}$ & & 37.95 & $1 \mathrm{~T}$ \\
\hline \multirow[t]{2}{*}{37.35} & $1 \mathrm{~L}$ & $37.43\}$ & \multirow{2}{*}{$1 \mathrm{~L}$} & & \\
\hline & & 37.20 & & & \\
\hline 36.06 & 1 & & & & \\
\hline \multirow[t]{4}{*}{32.70} & $4 \mathrm{R}$ & & & 32.58 & $4 \mathrm{~L}$ \\
\hline & & & & 30.68 & $1 \mathrm{C}$ \\
\hline & & $28.06\}$ & \multirow{2}{*}{1} & & \\
\hline & & $27.83\}$ & & & \\
\hline \multirow[t]{2}{*}{24.29} & 4 & $24.21\}$ & \multirow{2}{*}{4} & $24.22\}$ & $\{4 C$ \\
\hline & & $24.00\}$ & & $24.12\}$ & $4 \mathrm{~T}$ \\
\hline \multirow[t]{3}{*}{23.42} & $5 \mathrm{~L}$ & 23.59 ) & 5 & $23.29\}$ & $\{5 \mathrm{C}$ \\
\hline & & $23.30\}$ & $5 R$ & $23.23\}$ & S \\
\hline & & $23.24^{J}$ & $5 \mathrm{~L}$ & & \\
\hline 15.94 & 5 & & & 16.00 & $5 \mathrm{~T}$ \\
\hline
\end{tabular}

* Chemical shift from TMS (ppm) measured in $\mathrm{CDCl}_{3}$.

DM-1

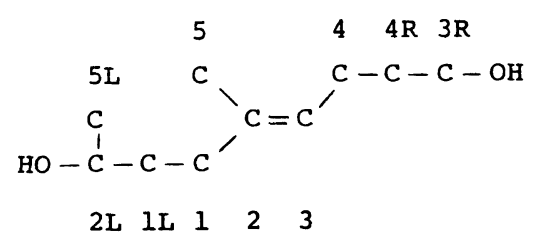

DM-2

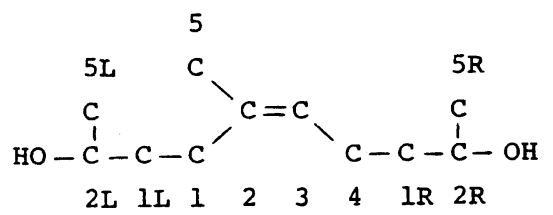

TM

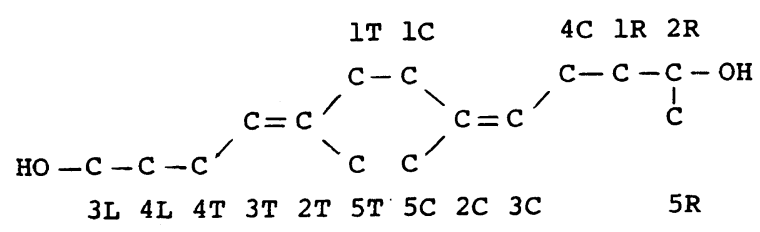


cis-1,4 and trans-1,4 polyisoprenes showed only 10 major peaks corresponding to the number of carbon atoms. These model compounds exhibited characteristic signals around 67 and $62 \mathrm{ppm}$, which were assigned to the carbons in $>\mathrm{CHOH}$ and $-\mathrm{CH}_{2} \mathrm{OH}$, respectively, by off-resonance measurements. In the spectrum of DM-2, the signals at $67.4-67.8 \mathrm{ppm}$ were assigned to the methylene carbons in secondary alcohols. The methyl carbon in the trans isoprene unit resonates around $16 \mathrm{ppm}$ and that in the cis unit around $23 \mathrm{ppm}^{8,9}$ The absence of signals around 62 and 16 ppm in Figure 4-A clearly shows that DM-2 consists of the cis isoprene unit and secondary alcohol residues.

DM-2 in methanol gave a simple spectrum showing only the 9 major signals in Figure 4-B. The difference between the spectra in deuterochloroform and methanol may be attributed to the intramolecular association of DM-2 in chloroform; the association between the terminal secondary hydroxyl groups enhances the stereochemical differences between the diastereomers, resulting in a spectrum that appears to indicate the presence of two components similar in structure. The difference is expected to be very small in methanol where the intramolecular association disappears. The presence of two secondary alcohol groups and the cis unit as well as the presence of two diastereomers indicate that DM-2 corresponds to structure (E). The signals in Figure 4 can be satisfactorily assigned to the carbons in (E), as shown in Table I.

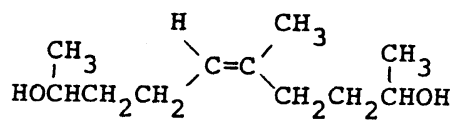

The ${ }^{13} \mathrm{C}$ NMR spectrum of DM-1 showed 10 major signals. The presence of the signals at 68.00 , 62.57, and $15.94 \mathrm{ppm}$ indicates that DM-1 consists of the trans isoprene unit with the primary and secondary alcohol residues. However, the ${ }^{13} \mathrm{C}$ NMR spectrum of DM-1 was different from that of the model compound prepared by partial ozonolysis of trans-1,4 polyisoprene; the signal at $32.70 \mathrm{ppm}$ in the spectrum of DM-1, which was assigned to the methylene carbon in $-\mathrm{CH}_{2} \mathrm{CH}_{2} \mathrm{OH}$, was not detected in the spectrum of the model compound. Therefore, it is reasonable to consider that the trans isoprene unit in DM-1 is linked in the head-to-head and tail-to-tail fashion, as shown by structure (F).

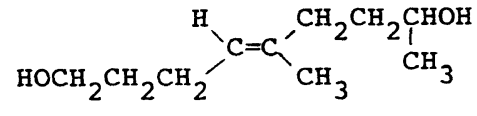

The ${ }^{13} \mathrm{C}$ NMR spectrum of TM exhibited 14 major signals, indicating TM to be a pure compound formed by the ozonolysis of a particular double bond in TMCDT. The signals at 16.00 and 23.23-23.29 ppm were assigned to methyl carbons in the trans and cis isoprene units, respectively. The presence of the trans and cis double bonds in TM was also confirmed by ${ }^{1} \mathrm{H}$ NMR measurements. The signals at 37.95 and $30.68 \mathrm{ppm}$ were assigned to the C-1 methylene carbons in the trans and cis isoprene units of the head-to-head linkage. These assignments are supported by the fact that in polyisoprene, the C-1 methylene carbon in the head-tohead linkage $(4,1-1,4)$ resonated at 38.22 (cis-trans) and 30.94 (trans-cis) ppm. ${ }^{7}$ The other signals were assigned to the carbons in structure $(G)$ by comparing the spectra of DM-1, DM-2, and the partial ozonolysis products of cis-1,4 and trans-1,4 polyisoprenes. The assignments of the signals in these partial ozonolysis products are shown in Table I.

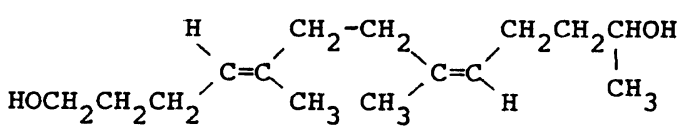

The results obtained here clearly show that only the structure (A) gives two dimers, (E) and (F), and trimer (G) by the selective ozonolysis of double bonds in TMCDT. Thus, it is concluded that TMCDT prepared with $\left(\mathrm{C}_{5} \mathrm{H}_{8}\right)_{2} \mathrm{Mg}-\mathrm{AlCl}_{3}-\mathrm{TiCl}_{4}-$ $\mathrm{CH}_{3} \mathrm{SCH}_{3}$ as a catalyst is 1,5,10-trimethylcis,trans,trans-1,5,9-cyclododecatriene.

The ${ }^{13} \mathrm{C}$ NMR spectrum of TMCDT was assigned as shown in Table II by off-resonance measurements and also by the comparison of the chemical shifts with those of farnesol isomers, geranylgeraniol isomers, and cis-trans isomerized polyisoprenes. ${ }^{9}$ The signal at $19.52 \mathrm{ppm}$, which is assigned to the methyl carbon in the trans isoprene unit, is characteristic of TMCDT, showing a $3 \mathrm{ppm}$ down-field shift, compared with the signal of linear isoprene units. This suggests that one of the methyl groups in the trans units is located in a very different steric environment as a result of the ring-strain and/or the steric effect of 
Table II. Assignment of the carbon atoms in TMCDT

\begin{tabular}{|c|c|}
\hline Chemical shift* & Assignment \\
\hline 136.36 & 1 \\
\hline 134.43$\}$ & $\int 10$ \\
\hline 133.42$\}$ & $\left\{\begin{array}{l}5 \\
5\end{array}\right.$ \\
\hline 127.43 & 2 \\
\hline 124.70$\}$ & 9 \\
\hline 124.35$\}$ & 6 \\
\hline 38.32 & 4 \\
\hline 36.78 & 11 \\
\hline 30.42 & 12 \\
\hline 29.64$\}$ & $\int 7$ \\
\hline 27.22$\}$ & $\{8$ \\
\hline 26.62 & 3 \\
\hline 23.41 & 13 \\
\hline 19.52$\}$ & $\{15$ \\
\hline 16.66$\}$ & $\{14$ \\
\hline
\end{tabular}

* Chemical shift from TMS (ppm) measured in $\mathrm{CDCl}_{3}$.

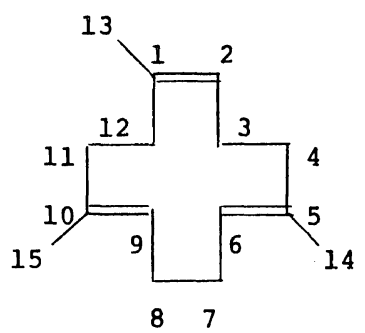

adjacent methyl groups. The presence of two types of trans methyl groups was also observed in the ${ }^{1} \mathrm{H}$ NMR spectrum of TMCDT (Figure 1).

It should be noted that the partial ozonolysis of TMCDT yields a single $\mathrm{C}_{15}$ compound (TM) and
$\mathrm{C}_{10}$ and $\mathrm{C}_{11}$ compounds (DM-1 and DM-2). This implies that the trans double bond at C-5 is selectively attacked at the first stage of ozonolysis and that the double bonds at C-1 and C-9 are subsequently attacked with nearly equal possibility. The conversion and selectivity of the partial ozonolysis reaction will be presented in the next paper.

\section{REFERENCES}

1. J. P. Cadlin and W. H. Janes, J. Chem. Soc. (C), 1856 (1968).

2. A. Misono, Y. Uchida, K. Furuhata, and S. Yoshida, Bull. Chem. Soc. Jpn., 42, 2303 (1969).

3. S. Watanabe, K. Suga, T. Fujita, and N. Takasaka, Yukagaku, 23, 24 (1974).

4. H. Morikawa and S. Kitazumi, Ind. Eng. Chem. Prod. Res. Dev., 18, 254 (1979).

5. Y. Tanaka and H. Sato, Polymer, 17, 413 (1976).

6. Y. Tanaka and H. Sato, Polymer, 17, 113 (1976).

7. H. Sato, A. Ono, and Y. Tanaka, Polymer, 18, 580 (1977).

8. Y. Tanaka and M. Takagi, Biochem. J., 183, 163 (1979).

9. Y. Tanaka, H. Sato, and A. Kageyu, Polymer, in press.

10. T. Taketomi, Japan Patent, 55-62026 (1980).

11. Y. Tanaka, J. Takeda, and K. Noguchi, Japan Patent 55-48211 (1980).

12. G. Bucci and T. Shimonazzi, J. Polym. Sci., C(7), 203 (1964).

13. H. L. McMurry and V. Thornton, Anal. Chem., 24, 318 (1952).

14. Y. Tanaka, H. Sato, and H. Iwasaki, Polymer, to be published.

15. H. Sato, K. Miyashita, A. Kageyu, and Y. Tanaka, J. Chromatogr., 237, 174 (1982). 